\title{
A neural network model for estimation soil temperature bases on limited meteorological parameters in selected provinces in Iraq
}

\author{
Ali M. Al-Salihi, Zahraa A. AL-Ramahy* \\ Department of Atmospheric Sciences, College of Science, Al-Mustansiriyah University, Baghdad, Iraq.
}

\begin{abstract}
Soil temperature is an important meteorological variable which plays a significant role in hydrological cycle. In present study, artificial intelligence technique employed for estimating for 3 days a head soil temperature estimation at 10 and $20 \mathrm{~cm}$ depth. Soil temperature daily data for the period 1 January 2012 to 31 December 2013 measured in three stations namely (Mosul, Baghdad and Muthanna) in Iraq. The training data set includes 616 days and the testing data includes 109 days. The Levenberg-Marquardt, Scaled Conjugate Gradient and Bayesian regularization algorithms. To evaluate the ANN models, Root mean square error (RMSE), Mean absolute error (MAE), Mean absolute percentage error (MAPE) and Correlation Coefficient (r) were determined. According to the four statistical indices were calculated of the optimum ANN model, it was ANN model (3) in Muthanaa station for the depth $10 \mathrm{~cm}$ and ANN model (3) in Baghdad station for the depth 20 were $\left(\mathrm{RMSE}=0.959^{\circ} \mathrm{C}, \mathrm{MAE}=0.725, \mathrm{MAPE}=4.293, \mathrm{R}=0.988\right)$ and ( $\mathrm{RMSE}=0.887^{\circ} \mathrm{C}, \mathrm{MAE}=0.704, \mathrm{MAPE}=4.239, \mathrm{R}=0.993$ ) respectively, theses statistical criteria shown the efficiency of artificial neural network for soil temperature estimation.
\end{abstract}

Key words: Soil temperature, artificial intelligence technique, a neutral network estimation.

\section{Introduction}

Soil temperature $\left(\mathrm{T}_{\mathrm{S}}\right)$ is a significant element in different research fields such as soil science, hydrology ,atmospheric sciences, agriculture and environmental studies[1]. It is a key parameter in agricultural management and engineering designs, the plants growth and soil physical processes influenced directly by soil temperature also it employed in thermal performance calculations for buildings in direct contact with the soil for estimating the efficiency of earth-to air heat exchangers [2]. Soil temperature controls on physical, chemical, and biological reactions in soil and has effective impacts on plant growth and soil structure formation [3,4]. [5] Indicated that daily and annual variations in soil temperature effect bio-chemical reactions in the soil, for example, rates of decay

Received: 15-09-2017; Accepted 02-10-2017; Published Online 06-10-2017

${ }^{*}$ Corresponding Author

Zahraa A. AL-Ramahy, Department of Atmospheric Sciences, College of Science, Al-Mustansiriyah University, Baghdad, Iraq

J. Appl. Adv. Res. • Vol. 2 - Issue 5 and mineralize of soil organic matter and emissions of Carbon dioxide. The seedling mortality, higher water demands, and high incidence and severity of plant diseases are the results for very high soil temperatures as recorded in tropical region weather conditions [3].

The patterns of soil temperature are controlled by different parameters, including region climate and topography, the size and structure of ground biomass and soil physical Characteristics [6]. For this reason, assessment and estimating of soil temperature actually are rather tricky, especially with shallow soil depths where soil temperature fluctuations are the largest [2]. This has led to a lot of researches to carry out approaches from simple to powerful for such estimation and modeling. The effective application of artificial neural networks (ANNs) to model dynamic systems in areas of science and engineering suggests that the ANN approach has become one of the commonly employed and powerful alternative techniques in time series forecasting [7]. Recently many researchers have concluded that the neural network approaches with 
its high efficiency to model non-linear relationships may propose a powerful alternative for soil temperature estimation [8]. Although the results of these researches [8-14], they still within the research environment. The results of these studies are promising and encouraging, several of mentioned researches employed meteorological data as inputs for the ANN Algorithms, except [11]who predicted soil temperatures of a base station employing soil temperatures of neighbor stations as a unique input parameter without any employing of the other meteorological parameters or elements related to soil properties. The aim of present study was to improve an ANN model in order to estimate daily soil temperature for diverse depths by employing different meteorological parameters as input in three cities namely Mosul, Baghdad and Muthanna.

\section{Material and Methodology}

\section{Site description}

The data employed in this paper were measured by the Iraqi Ministry of Agriculture at three measuring station of Iraq included Mosul, Baghdad and Muthanna. The daily soil temperature acquires with different depths included 10 and $20 \mathrm{~cm}$ cover the period (1 January 2012-31 December 2013). Geographical coordinates of the given stations are tabulated in Table 1. The study locations range from latitude 31.27 to 36.31 north and longitude 43.15 to 45.27 east. The map of the present study and area of the stations are shown in Fig. 2.

Table 1. Geographical coordinates of the study stations

\begin{tabular}{cccc}
\hline Station & latitude & longitude & Altitude (m) \\
\hline Mosul & 36.63 & 43.15 & 223 \\
Baghdad & 33.34 & 44.44 & 34 \\
Muthanna & 31.27 & 45.27 & 11 \\
\hline
\end{tabular}

Sketch of the monthly mean soil temperatures at $10 \mathrm{~cm}$ depth are shown in Fig. 1. It is important to note that the soil temperature fluctuates from moth to other and soil temperature appears through a year. For all considered stations. The maximum monthly mean soil temperature occurs in July; furthermore, the minimum monthly mean soil temperature occurs in December. The monthly mean soil temperature in July rang from as low as $32.4^{\circ} \mathrm{C}$ in Muthanna station to as high as $41.37^{\circ} \mathrm{C}$ in Mosul station. moreover, the monthly mean soil temperature in December rang from as low as $7.46^{\circ} \mathrm{C}$ in Mosul station to as high as $12.06^{\circ} \mathrm{C}$ in Muthanna station.

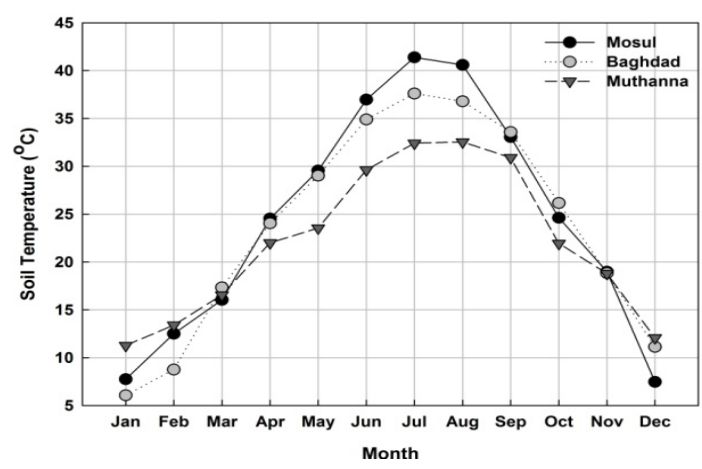

Fig. 1. Monthly mean soil temperatures of all stations at $10 \mathrm{~cm}$

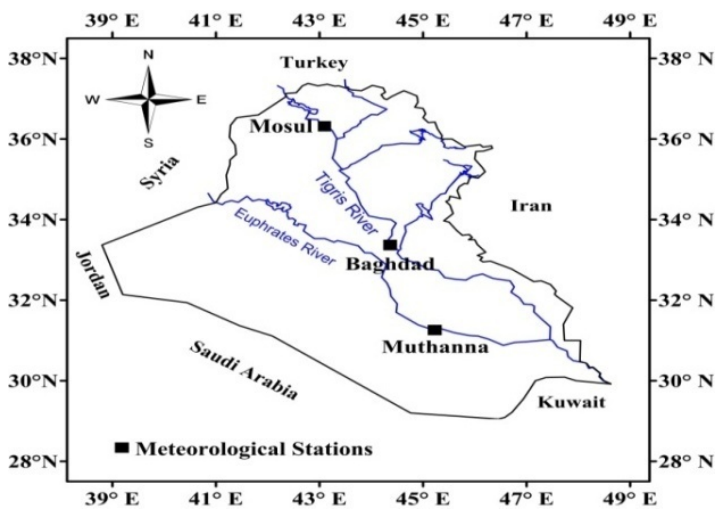

Fig. 2. The map of Iraq and site of the stations

\section{Artificial Neural Network}

ANN is a nonlinear mathematical modeling approach similar by human brain [9]. ANNS have been applying in many researches and various fields of mathematics, engineering, medicine, economics, psychology, neurology, regions Mineralization, in prediction of thermal and electrical [15-18]. [19] Additionally, Pointed to the widespread use of the ANN in meteorological applications. A typical ANN structure with three layers and one output neuron is shown in Fig. 3. ANN generality has input, output, and hidden middle layers. All the neurons connected to each other in parallel various weights. Every neuron receives signals from the neurons of the previous layer, weighted are linked by values between Nods, except the input layer. The output response in a neuron is calculated based on the weighted sum of all its inputs according to transfer function [20].

In present paper a feed forward back propagation model with sigmoid hidden neurons and linear output neurons is utilized to determine the relationships between measured soil 
A neural network model for estimation soil temperature

temperature and meteorological variables by iterative training procedure input and target data set without a priori knowledge and Various training algorithms were employed, Levenberg Marquardt (LM), Scaled Conjugate Gradient (SCG) and Bayesian regularization (BR) were applied and the best fit result was acquired.

The sigmoid transfer function can mathematically be presented as follows [21]:

$$
f(x)=\frac{1}{1+e^{-x}}
$$

The linear transfer function is defined as following:

$$
\Phi(u)=u
$$

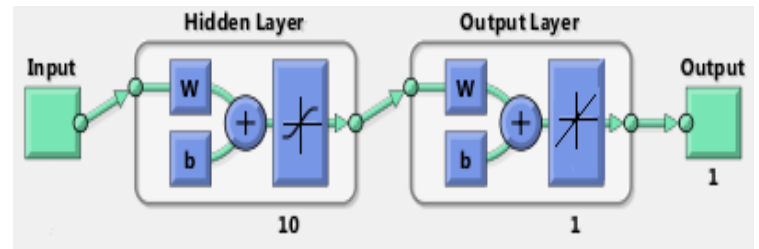

Fig. 3. Schematic diagram of neural network

\section{Statistical criteria}

In order to test and evaluate developed ANN models performance, Correlation Coefficient (R), Root Mean Square Error (RMSE), Mean Absolute Percentage Error (MAPE) and Mean Absolute Error (MAE) were used to compare the convergence between the measured and estimated values. The correlation coefficient $(\mathrm{R})$ is a common indicator for assessing the ANN models; the correlation coefficient $(\mathrm{R})$ was determined utilizing [22].

$$
\mathrm{R}=\frac{\sum\left(X_{i}-\bar{X}\right)\left(Y_{i}-\bar{X}\right)}{\sqrt{\sum\left(X_{i}-\bar{X}\right)^{2}+\left(X_{i}-\bar{X}\right)^{2}}}
$$

The RMSE is used to measure the estimation accuracy of the models [22].

$$
R M S E=\sqrt{\frac{1}{n} \sum_{i=1}^{n}\left(X_{i}-Y_{i}\right)^{2}}
$$

In addition, MAPE is define as follows [23].

$$
M A P E=\frac{1}{n} \sum_{i=1}^{n}\left|\frac{X_{i}-Y_{i}}{X_{i}}\right|
$$

Finally, the MAE is define as following [24].

$$
M A E=\frac{\sum_{i-1}^{n}\left|X_{i}-Y_{i}\right|}{n}
$$

Where $\mathrm{n}$ is the number of observations and $\mathrm{Xi}$ and $\mathrm{Yi}$ are the observed and estimated Values, respectively; $\bar{X}$ and $\bar{Y}$ are the average values of $X_{i}$ and $Y_{i}$.

\section{Results and Discussion}

The autocorrelation of the all soil temperature time series was applied for evaluating the impacts of previous soil temperatures at all depths. The lag was adjusted for soil temperatures from 1 to 10 days for at various depths at the study stations are shown in Figure 4. As illustrated, the autocorrelation coefficients at the applied lags are high and statistically significant for all employed soil depths. The gradually decreasing levels of the autocorrelation function indicate to a dominance of the autoregressive process. A deeper view at the autocorrelation analysis for diverse depths confirms a powerful memory of the soil temperature time series in the deeper levels of soil than that in the nearest to surface. As can be observed from Figure 1. At the humid cities (Mosul and Baghdad) the soil temperature at $10 \mathrm{~cm}$ depth has the highest autocorrelation coefficient at lag 1 , and thereafter (from lag 2 to lag 10) the soil temperature at 20 $\mathrm{cm}$ depth shows the highest autocorrelation. At the arid city (Muthanna), the presence of a dominant autoregressive process is more evident at $20 \mathrm{~cm}$ depth compared with shallower depths. The mentioned autocorrelations as an indicative of high persistence are advantageous for developing different types of artificial neural network models.

A tow year daily data measurements (1January 2012 -31December 2013) of the soil temperature at depth of $10,20 \mathrm{~cm}$ air temperature, relative humidity and solar radiation employed in current study, for each location the data were separated in three partitions included training, validation and testing data set. The first was $70 \%$ of the whole data (510 daily values) were used for training, second $15 \%$ were for validation (109 daily values) finally the rest $15 \%$ were testing data (109 daily values). 
The application of sigmoid function in hidden layer and linear function in output layer. The data must be normalized into the range $[0,1]$ before applying the ANN Methodology. It was found to be useful to normalize the time series to the range $[0.05,0.95]$ to avoid the problem of output signal overlapping that can occasionally be encountered in ANN approaches [25]. Therefore, the data were normalized within the range $0.05 \_095$ as follows:

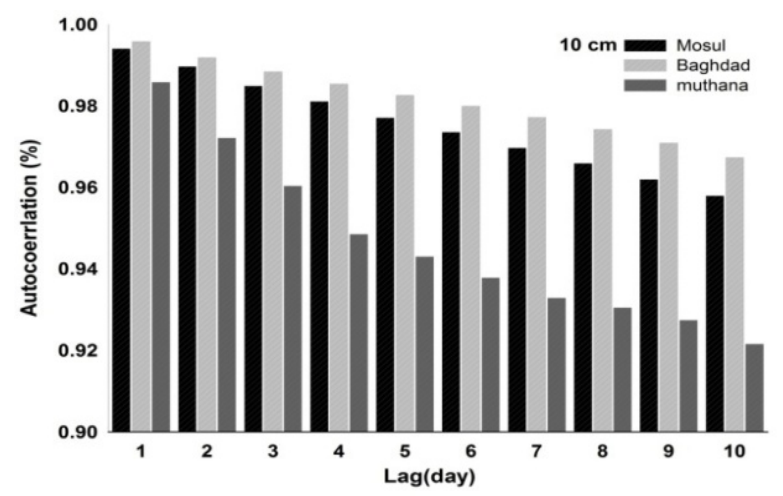

$$
X_{n}=0.05+0.9 \frac{X_{o}-X_{\min }}{X_{\max }-X_{\min }}
$$

Where $X_{n}$ and $X_{o}$ are the normalized and the main inputs at a select depth/station, and $X_{\min }$ and $\mathrm{X}_{\max }$ are the minimum and maximum of input at a select depth/station, respectively.

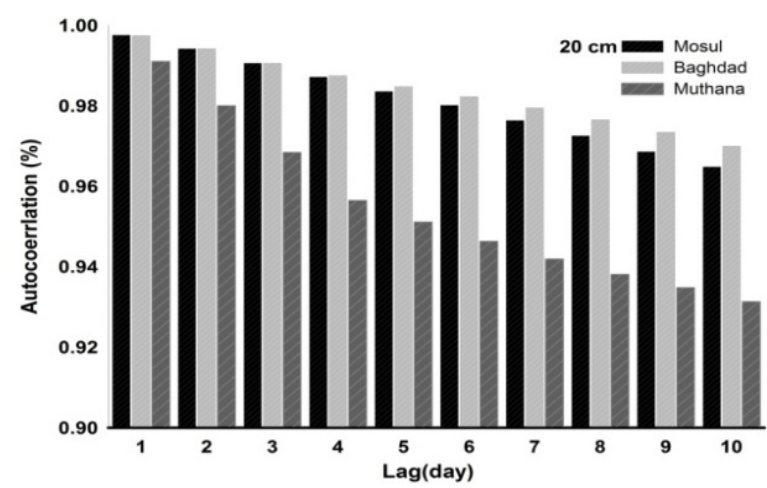

Fig. 4. Autocorrelation function of soil temperature time series at various depths at considered stations

Table 2. Minimum and maximum values of input and output parameters

\begin{tabular}{cccc}
\hline Station & Parameter & $\mathbf{X}_{\min }$ & $\mathbf{X}_{\max }$ \\
\hline & Soil Temperature10 & 3.87 & 43.79 \\
& Soil Temperature20 & 4.83 & 40.15 \\
& Air Temperature & 0.525 & 40.835 \\
& Relative Humidity & 7.83 & 92.8 \\
& Solar Radiation & 67.62 & 356.56 \\
& Soil Temperature 10 & 4.04 & 42.41 \\
& Soil Temperature 20 & 8.54 & 40.87 \\
& Air Temperature & 3.19 & 39.51 \\
& Relative Humidity & 11.135 & 88.18 \\
& Solar Radiation & 46.58 & 346.1 \\
& Soil Temperature 10 & 6.89 & 38.15 \\
& Soil Temperature 20 & 7.49 & 36.71 \\
& Air Temperature & 5.705 & 39.73 \\
& Relative Humidity & 13.17 & 88.845 \\
& Solar Radiation & 59.44 & 422.66
\end{tabular}

The minimum and maximum values of input and output parameters are shown in table 2 . Normalization improves training efficiency through training inputs [26]. ANN architecture utilize in current study is illustrate in Fig. 3. In order to determine the optimal network architecture, different structures of predictive models designed by MATLAB 15a software. For this reason, the estimations were performance by taking different number of algorithms. Model was validated by testing values, which was not used during the training process. Various training algorithms were employed and the best fit result was gained. In this model, Levenberg - Marquardt (LM), Scaled Conjugate Gradient and Bayesian regularization were applied. Neurons in the input layer have no transfer function. Logistic sigmoid transfer function (logsig) and linear transfer function (purelin) were used in the hidden layers and output layer of the network as an activation function, respectively. The ANN architecture consists of an input layer, one hidden layer with ten neurons and an output layer. 
A neural network model for estimation soil temperature

The performance of ANN model for 3 days ahead soil temperature estimation at 10 and $20 \mathrm{~cm}$ depth which presented the best output for all considered stations during testing procedure is illustrated in a time series of figures 5 , it is clear that the ANN models estimations closely follow corresponding measured values. A closer look at the tow time series (estimated and measured) for Muthanaa station (Fig. 5) reveals that the ANN not only very well captures the major trends in the soil
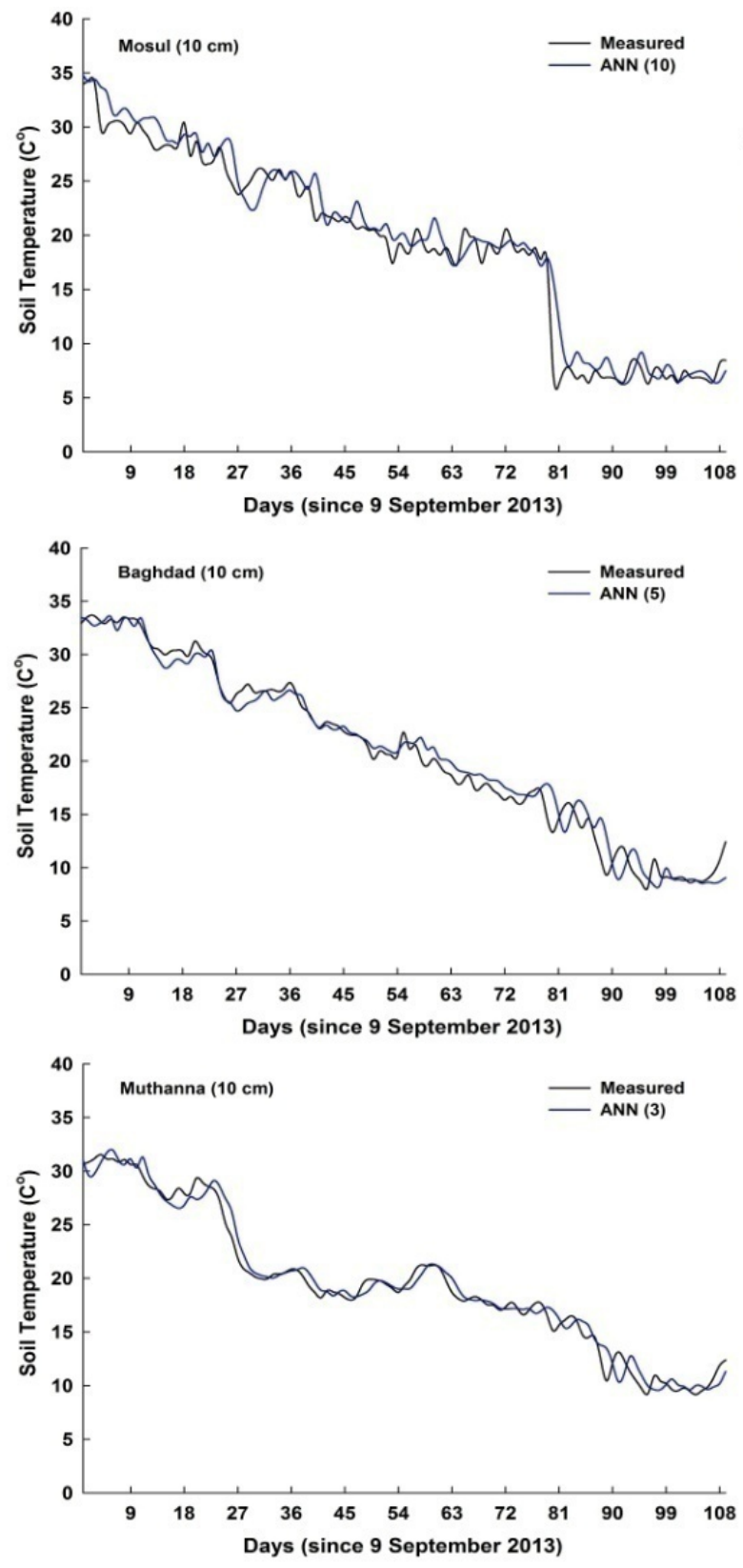

temperature series but also reasonably preserves the minor fluctuations. As can be seen, even extreme values are very well estimated and estimated values are much closer to and almost indistinguishable from the measured values. The good agreement between the measured and estimated series can also be revealed by plotting the scatter diagrams, as shown in Fig. 6 . As seen from the scatter plots, the ANN models performance are accurate and good, where all data points are quite near the line of agreement.
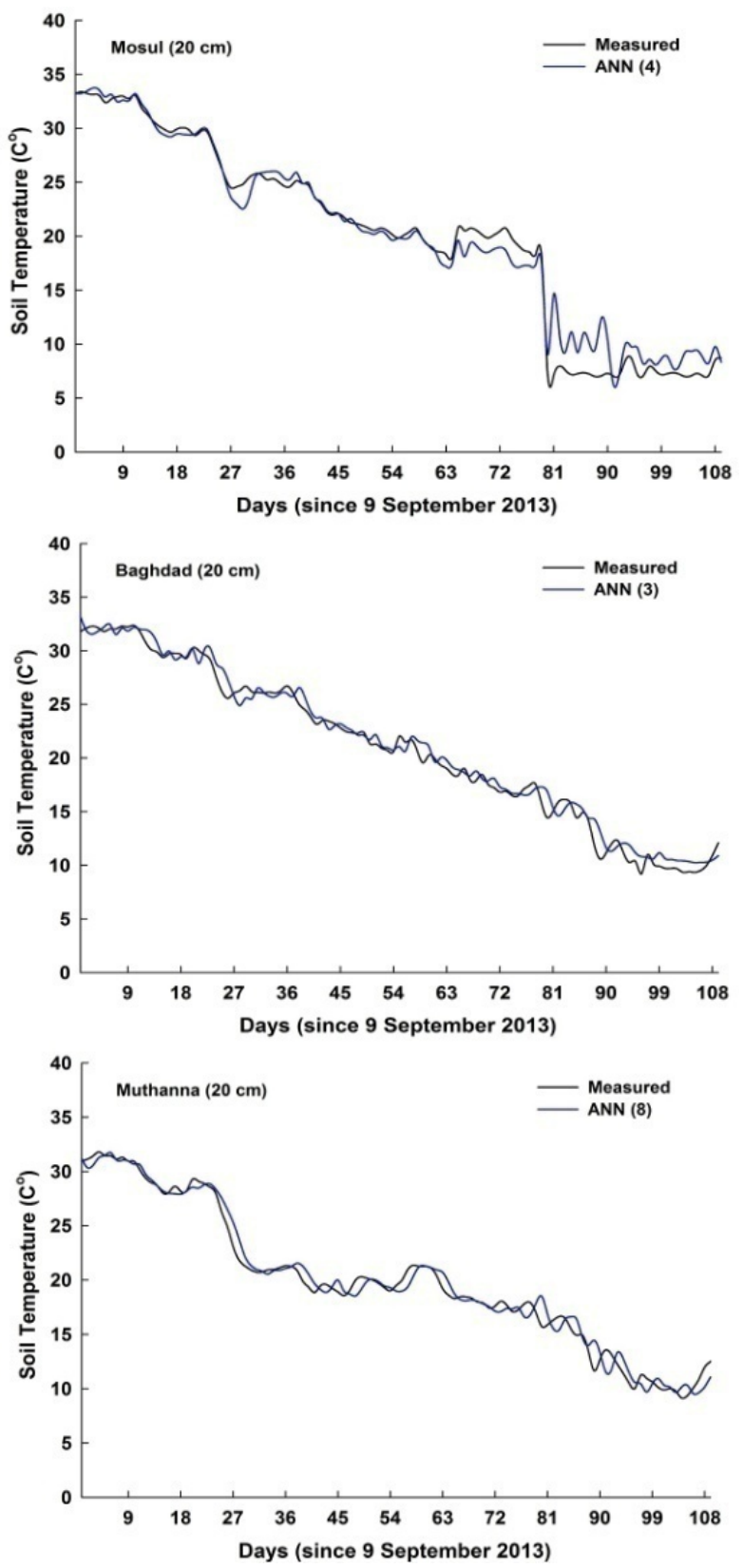

Fig 5. Time series comparison of the measured and artificial neural network (ANN) forecasted daily soil temperature series at $10 \mathrm{~cm}$ and $20 \mathrm{~cm}$ depth in the testing period at given station 

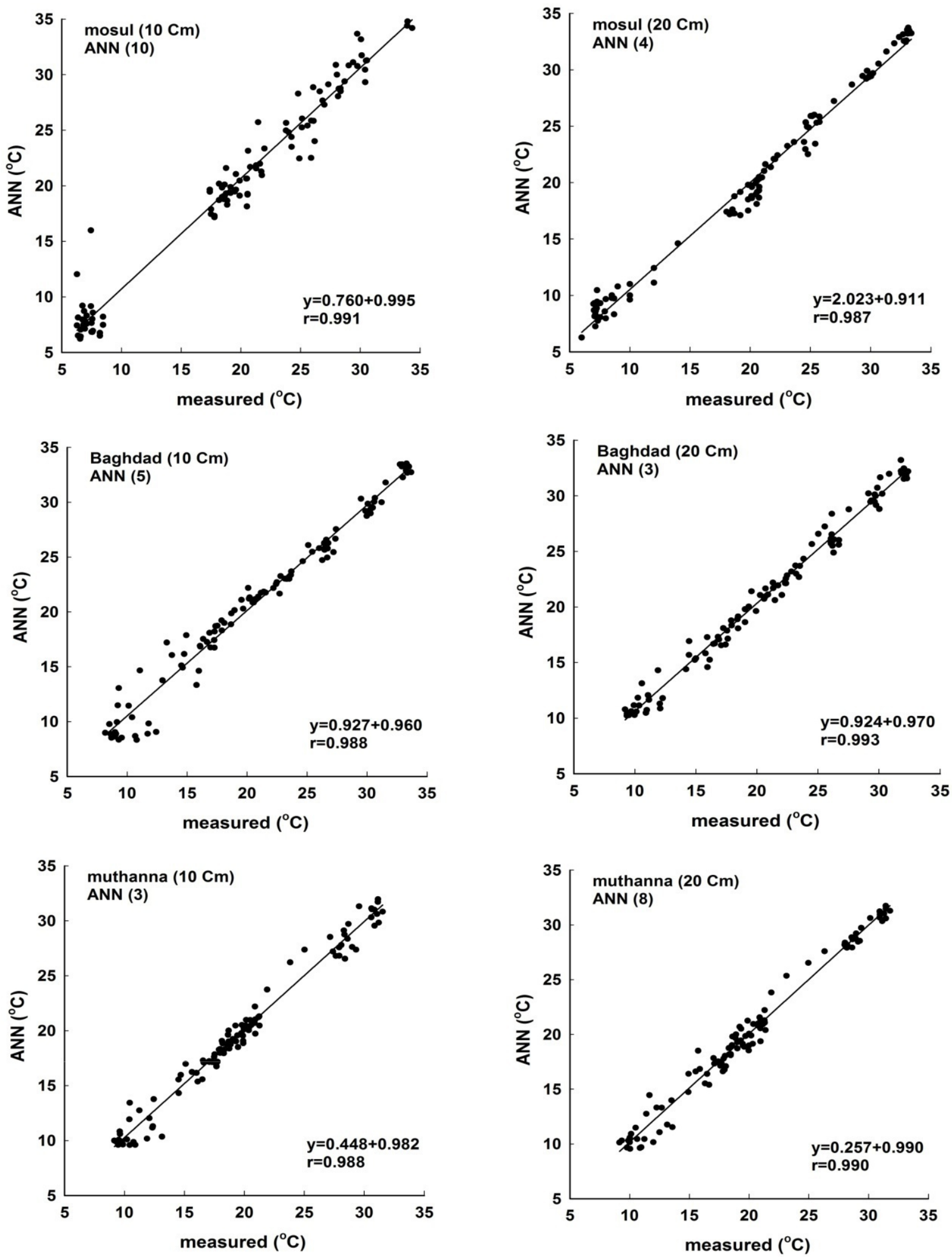

Fig 6. Scatter plot of the measured and artificial neural network (ANN) forecasted daily soil temperature series at $10 \mathrm{~cm}$ and $20 \mathrm{~cm}$ depth in the testing period at given station 
A neural network model for estimation soil temperature

The validation criteria of the proposed ANN models for 3 days ahead soil temperature forecasting at various depths are tabulated in Tables 3, 4 and 5. As shown, the correlation coefficient of all proposed ANN models for both depths in all considered stations are higher than 0.97, indicating the high accuracy of models outputs. According to [27], a correlation coefficient $\geq 0.95$ is generally considered very satisfactory, The ANN model (3)with $10 \mathrm{~cm}$ depth presents the optimum forecasting of the soil depths
$\left(\mathrm{RMSE}=0.959^{\circ} \mathrm{C}, \quad \mathrm{MAE}=0.725, \quad \mathrm{MAPE}=4.293\right.$, $\mathrm{R}=0.988$ ) for Muthnna station, whereas ANN model (3) gives most accuracy for $20 \mathrm{~cm}$ depth $\left(\mathrm{RMSE}=0.887^{\circ} \mathrm{C}, \quad \mathrm{MAE}=0.704, \quad \mathrm{MAPE}=4.239\right.$, $\mathrm{R}=0.993$ ) in Baghdad station. Generally, the performance level of the ANN models increased with the increase of the soil depth. The including of air temperature improved the output results, particularly in the shallow depths, which are more affected by atmospheric parameters variation.

Table 3. Performance of ANN models for 3 days a head soil temperature estimating at mosul station

\begin{tabular}{llllllllllll}
\hline Depth & Model & RMSE & MAE & MAPE & R & Depth & Model & RMSE & MAE & MAPE & R \\
\hline \multirow{6}{*}{ LM(1) } & 1.516 & 0.963 & 7.733 & 0.984 & & SCG(1) & 1.853 & 1.113 & 8.227 & 0.980 \\
& SCG(2) & 1.296 & 0.872 & 6.643 & 0.989 & & SCG(2) & 1.920 & 1.041 & 8.405 & 0.979 \\
& SCG(3) & 1.221 & 0.928 & 6.911 & 0.990 & & LM(3) & 1.890 & 1.038 & 7.939 & 0.980 \\
& SCG(4) & 1.610 & 1.134 & 9.289 & 0.982 & & SCG(4) & 1.538 & 1.029 & 9.800 & 0.987 \\
& BR(5) & 1.355 & 0.858 & 6.691 & 0.987 & & SCG(5) & 1.861 & 1.015 & 7.867 & 0.979 \\
& BR(6) & 1.500 & 0.947 & 7.714 & 0.984 & 20 & SCG(6) & 1.591 & 1.099 & 8.454 & 0.984 \\
& LM(7) & 1.462 & 1.041 & 7.657 & 0.985 & & BR(7) & 1.890 & 1.071 & 8.161 & 0.979 \\
& SCG(8) & 1.373 & 0.962 & 7.186 & 0.987 & & SCG(8) & 1.921 & 1.068 & 8.376 & 0.979 \\
& SCG(9) & 1.501 & 1.046 & 8.018 & 0.987 & & SCG(9) & 1.586 & 1.005 & 7.464 & 0.985 \\
& SCG(10) & 1.195 & 0.894 & 6.014 & 0.991 & & LM(10) & 1.920 & 1.064 & 7.990 & 0.979 \\
& SCG(11) & 1.211 & 0.877 & 7.030 & 0.991 & & BR(11) & 1.907 & 1.054 & 7.973 & 0.979 \\
& BR(12) & 1.613 & 1.023 & 8.363 & 0.983 & & LM(12) & 1.926 & 1.027 & 7.877 & 0.979 \\
\hline
\end{tabular}

Table 4. Performance of ANN models for 3 days a head soil temperature estimating at Baghdad station

\begin{tabular}{llllllllllll}
\hline Depth & Model & RMSE & MAE & MAPE & R & Depth & Model & RMSE & MAE & MAPE & R \\
\hline \multirow{6}{*}{ LM(1) } & 1.329 & 1.013 & 5.775 & 0.987 & & BR(1) & 1.195 & 0.915 & 5.453 & 0.988 \\
& LM(2) & 1.296 & 0.978 & 5.967 & 0.987 & & SCG(2) & 1.099 & 0.856 & 4.925 & 0.990 \\
& LM(3) & 1.411 & 1.097 & 6.574 & 0.985 & & SCG(3) & 0.887 & 0.704 & 4.239 & 0.993 \\
& BR(4) & 1.320 & 1.022 & 6.252 & 0.987 & & LM(4) & 1.186 & 0.908 & 5.407 & 0.988 \\
& SCG(5) & 1.219 & 0.885 & 5.702 & 0.988 & & BR(5) & 1.274 & 0.978 & 5.647 & 0.987 \\
& LM(6) & 1.362 & 1.047 & 6.232 & 0.986 & 20 & SCG(6) & 1.221 & 0.943 & 5.582 & 0.988 \\
& BR(7) & 1.415 & 1.075 & 6.377 & 0.985 & & BR(7) & 1.272 & 0.962 & 5.654 & 0.987 \\
& BR(8) & 1.402 & 1.072 & 6.528 & 0.986 & & BR(8) & 1.251 & 0.964 & 5.574 & 0.988 \\
& LM(9) & 1.411 & 1.084 & 6.695 & 0.985 & & BR(9) & 1.270 & 0.976 & 5.629 & 0.987 \\
& BR(10) & 1.301 & 1.033 & 6.148 & 0.978 & & BR(10) & 1.271 & 0.951 & 5.614 & 0.987 \\
& SCG(11) & 1.412 & 1.064 & 6.694 & 0.984 & & LM(11) & 1.237 & 0.941 & 5.547 & 0.987 \\
& BR(12) & 1.396 & 1.078 & 6.429 & 0.985 & & SCG(12) & 1.184 & 0.911 & 5.215 & 0.988 \\
\hline
\end{tabular}


Ali M. Al-Salihi, Zahraa A. AL-Ramahy (2017)

Table 5. Performance of ANN models for 3 days a head soil temperature estimating at Muthannastation

\begin{tabular}{llllllllllll}
\hline Depth & Model & RMSE & MAE & MAPE & R & Depth & Model & RMSE & MAE & $\begin{array}{l}\text { MAP } \\
\text { E }\end{array}$ & R \\
\hline \multirow{4}{*}{ BR(1) } & 1.302 & 0.988 & 5.932 & $\mathbf{0 . 9 8 0}$ & & SCG(1) & 1.242 & 0.992 & 5.750 & 0.983 \\
& SCG(2) & 1.196 & 0.944 & 5.374 & 0.984 & & LM(2) & 1378 & 1.054 & 6.154 & 0.979 \\
& SCG(3) & 0.959 & 0.725 & 4.293 & 0.988 & & SCG(3) & 1.372 & 1.059 & 6.047 & 0.980 \\
& LM(4) & 1.307 & 0.987 & 5.817 & 0.980 & & BR(4) & 1.270 & 0.985 & 5.718 & 0.982 \\
& LM(5) & 1.431 & 1.094 & 6.822 & 0.976 & & LM(5) & 1.381 & 1.051 & 6.129 & 0.978 \\
& SCG(6) & 1.378 & 1.108 & 6.413 & 0.977 & 20 & LM(6) & 1.295 & 0.997 & 5.840 & 0.981 \\
& SCG(7) & 1.437 & 1.124 & 6.728 & 0.975 & & LM(7) & 1.348 & 1.052 & 6.115 & 0.980 \\
& LM(8) & 1.454 & 1.095 & 6.635 & 0.976 & & SCG(8) & 0.895 & 0.668 & 4.081 & 0.990 \\
& SCG(9) & 1.317 & 1.053 & 6.588 & 0.981 & & LM(9) & 1.378 & 1.050 & 6.114 & 0.979 \\
& SCG(10) & 1.435 & 1.111 & 6.670 & 0.976 & & SCG(10) & 1.190 & 0.931 & 5.541 & 0.984 \\
& SCG(11) & 1.409 & 1.116 & 6.631 & 0.979 & & SCG(11) & 1.379 & 1.057 & 6.287 & 0.980 \\
& LM(12) & 1.419 & 1.111 & 6.655 & 0.976 & & SCG(12) & 1.274 & 0.958 & 5.450 & 0.982 \\
\hline
\end{tabular}

\section{Conclusion}

The employing of the ANN technique for daily soil temperature estimation is very important for agriculture. in present study, ANN approach has been used for estimation for 3 day ahead soil temperature estimation for different two depth included $10 \mathrm{~cm}$ and $20 \mathrm{~cm}$.the results of evaluation and comparative study refers to that the ANN based on scaled conjugate gradient at $10 \mathrm{~cm}$, $20 \mathrm{~cm}$ in muthana and Baghdadstation respectively showed a best performance of soil temperature estimation accordant to the employed statistical criteria, this study conform the powerful ability of ANN to estimate soil temperature and suggest to use ANN technique in different area in Iraq.

\section{References}

1. Jackson, T., et al. Measuring soil temperature and moisture using wireless MEMS sensors. Measurement, 2008. 41(4): 381-390.

2. Mihalakakou, G., On estimating soil surface temperature profiles. Energy and Buildings, 2002. 34(3): 251-259.

3. Tenge, A., et al., Diurnal soil temperature fluctuations for different erosion classes of an oxisol at Mlingano, Tanzania. Soil and Tillage Research, 1998. 49(3): p. 211-217.

4. Brooks, P.D., D. McKnight, and K. Elder, Carbon limitation of soil respiration under winter snowpacks: potential feedbacks between growing season and winter carbon fluxes. Global Change Biology, 2005. 11(2): 231-238.

5. Paul, K.I., et al., Soil temperature under forests: a simple model for predicting soil temperature under a range of forest types. Agricultural and Forest Meteorology, 2004. 121(3): 167-182.

6. Bond-Lamberty, B., C. Wang, and S.T. Gower, Spatiotemporal measurement and modeling of stand-level boreal forest soil temperatures. Agricultural and Forest Meteorology, 2005. 131(1): 27-40.

7. Yadav, D., R. Naresh, and V. Sharma, Stream flow forecasting using Levenberg-Marquardt algorithm approach. International Journal of Water Resources and Environmental Engineering, 2011. 3(1): 30-40.

8. Wu, W., et al., Spatiotemporal modeling of monthly soil temperature using artificial neural networks. Theoretical and Applied Climatology, 2013. 113(3-4): 481-494.

9. Ozturk, M., O. Salman, and M. Koc, Artificial neural network model for estimating the soil temperature. Canadian Journal of Soil Science, 2011. 91(4): 551-562.

10. Tabari, H., A.-A. Sabziparvar, and M. Ahmadi, Comparison of artificial neural network and multivariate linear regression methods for estimation of daily soil temperature in an arid region. Meteorology and Atmospheric Physics, 2011. 110(3-4): 135-142. 
11. Bilgili, M., B. Sahin, and L. Sangun, Estimating soil temperature using neighboring station data via multi-nonlinear regression and artificial neural network models. Environmental monitoring and assessment, 2013. 185(1): 347-358.

12. Talaee, P.H., Daily soil temperature modeling using neuro-fuzzy approach. Theoretical and applied climatology, 2014. 118(3): 481-489.

13. Kim, S. and V.P. Singh, Modeling daily soil temperature using data-driven models and spatial distribution. Theoretical and applied climatology, 2014. 118(3): 465-479.

14. Kisi, O., M. Tombul, and M.Z. Kermani, Modeling soil temperatures at different depths by using three different neural computing techniques. Theoretical and Applied Climatology, 2015. 121(1-2): 377-387.

15. Kalogirou, S.A., Artificial neural networks in renewable energy systems applications: a review. Renewable and sustainable energy reviews, 2001. 5(4): 373-401.

16. Şenkal, O., et al., Precipitable water modelling using artificial neural network in Cukurova region. Environmental monitoring and assessment, 2012. 184(1): 141-147.

17. Kişi, Ö., River flow modeling using artificial neural networks. Journal of Hydrologic Engineering, 2004. 9(1): 60-63.

18. Mendes, D. and J.A. Marengo, Temporal downscaling: a comparison between artificial neural network and autocorrelation techniques over the Amazon Basin in present and future climate change scenarios. Theoretical and Applied Climatology, 2010. 100(3-4): 413-421.
19. Rahimikhoob, A., Estimating daily pan evaporation using artificial neural network in a semi-arid environment. Theoretical and applied climatology, 2009. 98(1-2): 101-105.

20. Maqsood, I., et al., Application of soft computing models to hourly weather analysis in southern Saskatchewan, Canada. Engineering Applications of Artificial Intelligence, 2005. 18(1): 115-125.

21. Dawson, C.W., et al., Flood estimation at ungauged sites using artificial neural networks. Journal of Hydrology, 2006. 319(1): 391-409.

22. Abyaneh, H.Z., et al., Assessment of groundwater corrosivity in Hamedan Province, Iran using an adaptive neuro-fuzzy inference system (ANFIS). Geosciences Journal, 2011. 15(4): 433-439.

23. Bilgili, M., Prediction of soil temperature using regression and artificial neural network models. Meteorology and atmospheric physics, 2010. 110(1-2): 59-70.

24. Öztürk, S., İstatistiksel Regresyon Yöntemlerinin Farklı Veri Gruplarına Uygulanması Üzerine Bir Analiz. Gümüşhane Üniversitesi Fen Bilimleri Enstitüsü Dergisi, 2012. 2(2).

25. Smith, M., Neural networks for statistical modeling. 1993: Thomson Learning.

26. Krauss, G., J. Kindangen, and P. Depecker, Using artificial neural networks to predict interior velocity coefficients. Building and environment, 1997. 32(4): 295-303.

27. Shamseldin, A.Y., Application of a neural network technique to rainfall-runoff modelling. Journal of Hydrology, 1997. 199(3-4): 272-294. 